\title{
Associating Use of Digital Technology and Self-Reported Health Problems among College Going Students in Delhi-NCR, India
}

마물

\section{SHEETAL BAWNOO HANDOO*1, RICHA RATHOR²}

INTRODUCTION: The increased use of digital media among college students has the tendency to cause various health problems based on the duration and medium used.

AIM: To assess the use of digital technology and self- reported health problems among college going students in Delhi-NCR, India MATERIALS AND METHODS: Data was collected using a pre-tested and pre-validated questionnaire which was divided into three sections. The first section contained seven questions regarding demographic details, the second contained three questions regarding the device used, hours spent and the type of media assessed, while the third contained twelve questions regarding self-reported adverse events while accessing digital media. Statistical tests involved the Shapiro-Wilk test, Independent samples t-test, multivariate linear regression and the Pearson's correlation coefficient. The analysis was done using SPSS version 19.0.

RESULTS: Responses of 717 students were included in the final analysis. Most of the students were between $17-19$ years (53.9\%), the primary device used was smartphone (91.8\%). Most students used their device for $>1-4$ hours $(34.6 \%)$. The most common selfreported symptom was back and/or neck pain (18.4\%) followed by sleep issues/ insomnia (17.7\%) and headache (17.3). Multiple linear regression model revealed that good knowledge scores were significantly associated with age $(\mathrm{p}=0.04)$ and the duration of device used $(\mathrm{p}=0.02)$. A positive, linear, great strength of association $(\mathrm{r}:+0.747)$ and a significant relationship $(\mathrm{p}=0.037)$ was found between self-reported health problems and the hours of device usage.

CONCLUSION: It is advised that college students be advised regarding the ill effects of digital medium without taking proper precautions.

KEYWORDS: Health, Technology, Back Pain

\section{INTRODUCTION}

The use of digital media has grown exponentially over the years and most of its usage can be attributed to the use of the smart phone, which was once looked upon as a luxury commodity. ${ }^{1}$ As per a recent study, young individuals have been pervasively using digital medium tools and especially social media for a variety of reasons which include entertainment, social enhancement, identity formation, and maintaining interpersonal connections. $^{2}$

The launch of affordable $4 \mathrm{G}$ services and devices in the Indian market has made high speed constant internet a reality for all. It finds use in fields of education, marketing, communication and so forth. Various researchers have put forth the suggestion that social media has the ability provide users with a platform that overcomes barriers of distance and time to connect and reconnect with others and thereby expand and strengthen their offline networks and interactions. ${ }^{3-5}$
The world wide web today has approximately more than one billion active users, and it is estimated that in the future, this number will significantly increase, especially in developing countries. This is supported by the fact that the use of social media is prevalent across all ages and professions and is pervasive around the world. ${ }^{6}$

However, few researchers have associated use of digital medium with several psychiatric disorders, examples of which include depressive symptoms, anxiety, and low self-esteem. Such effects depend on many factors such as the type and duration of the used device. A few milder and initial symptoms while using digital media include headache, eye pain, postural problems, insomnia, etc. ${ }^{7}$

With the use of digital content on the rise, users are spending an increased time on their devices, and this 
has the potential to affect their health and hence, the present study was undertaken with the aim to assess the use of digital technology and self- reported health problems among college going students in Delhi-NCR, India

\section{MATERIALS AND METHOD}

Prior to implementation of this study, the questionnaire designing, validation, pilot study and strategies for maximum participation were discussed. The main instrument to collect data was a pre-validated and pre-tested questionnaire containing three sections and after ethical approval, was distributed to students. Necessary permissions from the management of the concerned institutions were duly obtained. The first section contained seven questions regarding demographic details, the second contained three questions regarding the device used, hours spent and the type of media assessed, while the third contained twelve questions regarding self-reported adverse events while accessing digital media. The first page of the questionnaire assured confidentiality of data, informed the study objectives and stated that participation was purely voluntary. The consent to participate (inclusion criteria) was implied when the students agreed to answer the questionnaire and they had complete freedom to decline at any time. Access to data was only to the principal investigator and no personal details (email id, phone number, name etc.) were asked. Among total submissions, if a student failed to answer $\geq 1$ question, it was excluded from the analysis.

The study duration was from $01^{\text {st }}$ October 2016 to $28^{\text {th }}$ February, 2017 (5 months) through convenience sampling so that maximum participation could be ensured. The questionnaire was distributed personally and a pilot study was done on 25 participants to validate the questionnaire and its Cronbach alpha $(\alpha)$ was found to be .69. The pilot study responses and incomplete responses were excluded from the main analysis.

Data analysis included tests for normalcy Shapiro-Wilk test, Independent samples t-test, multivariate linear regression and the Pearson's correlation coefficient. Coded data was sent to the statistician so that confidentially of the data could be maintained. The analysis was done using SPSS version 19.0. ${ }^{8}$

\section{RESULTS}

The response rate of the present study was $79.8 \%$ as of a total of 899 responses recorded, only 717 were complete responses and hence, were subsequently analysed.

\section{Age characteristics and device used for accessing} social media (Table 1 )

Most of the students belonged to $17-19$ years (53.9\%) while the least belonged to $>25$ years of age (14.4\%). The primary device used for accessing social media was smartphone (91.8\%) followed by laptop (6.8\%) and tablet (1.4\%).

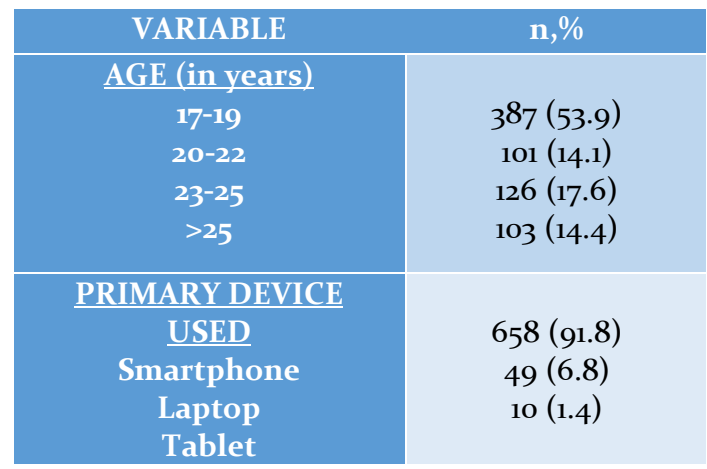

Table 1. Age Characteristics and Device Used for Accessing Social Media among the Students

\section{Device duration and Use (Table 2)}

It was observed that most students used their device for $>1-4$ hours (34.6\%). Only $7.7 \%$ of the participants used their device for $>8$ hours. The most commonly used digital medium used was Social media (35.9\%) followed by YouTube (24.8\%), music(14.1\%) and movies(11.4\%).

\begin{tabular}{|c|c|}
\hline VARIABLE & $\mathbf{n}, \%$ \\
\hline \multicolumn{2}{|l|}{ DAILY USAGE OF } \\
\hline DEVICE & $134(18.7)$ \\
\hline$<1$ Hour & $248(34.6)$ \\
\hline$>1-4$ Hours & $147(20.5)$ \\
\hline 4-6 hours & $133(18.5)$ \\
\hline 6-8 hours & $55(7.7)$ \\
\hline$>8$ hours & \\
\hline \multicolumn{2}{|l|}{ MAIN USE } \\
\hline $\begin{array}{l}\text { Social Media } \\
\text { (Including Social }\end{array}$ & $258(35.9)$ \\
\hline Messaging Apps) & $47(6.5)$ \\
\hline Games & $178(24.8)$ \\
\hline Youtube & $82(11.4)$ \\
\hline Movies & $101(14.1)$ \\
\hline Music & $51(7 \cdot 3)$ \\
\hline Other & \\
\hline
\end{tabular}

Table 2. Device Duration and Use among Students 


\begin{tabular}{|c|c|c|c|c|c|c|c|}
\hline $\begin{array}{l}\text { Self-Reported } \\
\text { Symptom(s) }\end{array}$ & $<\mathbf{l}$ hour & 1-4 Hours & 4-6 hours & 6-8 hours & $>8$ hours & Total & $\begin{array}{c}\mathbf{p} \\
\text { Value }\end{array}$ \\
\hline Headache & $15(11.2 \%)$ & $43(17 \cdot 3 \%)$ & $36(24.5 \%)$ & $21(15.8 \%)$ & $9(16.4 \%)$ & $124(17 \cdot 3 \%)$ & NS \\
\hline Eye Pain & $26(19.4 \%)$ & $56(22.5 \%)$ & $18(12.2 \%)$ & $10(7 \cdot 5 \%)$ & $7(12.7 \%)$ & $117(16.3 \%)$ & $0.01^{*}$ \\
\hline Blurry Vision & $12(8.9 \%)$ & $9(3.6 \%)$ & $13(8.8 \%)$ & $11(8.3 \%)$ & $5(9.1 \%)$ & $50(6.9 \%)$ & NS \\
\hline $\begin{array}{l}\text { Sleep Issues/ } \\
\text { Insomnia }\end{array}$ & $34(25.8 \%)$ & $35(14.1 \%)$ & $23(15.6 \%)$ & $29(21.8 \%)$ & $6(10.9 \%)$ & $127(17 \cdot 7 \%)$ & $0.04^{*}$ \\
\hline $\begin{array}{l}\text { Back and/or } \\
\text { Neck pain }\end{array}$ & $12(8.9 \%)$ & $58(23.4 \%)$ & $\begin{array}{c}33 \\
(22.4 \%)\end{array}$ & $20(15.0 \%)$ & $9(16.4 \%)$ & $132(18.4 \%)$ & $0.04^{*}$ \\
\hline Painful Fingers & $22(16.4 \%)$ & $12(4.8 \%)$ & $5(3.4 \%)$ & $19(14 \cdot 3 \%)$ & $6(10.9 \%)$ & $64(8.9 \%)$ & NS \\
\hline $\begin{array}{c}\text { Tiredness and/or } \\
\text { Lethargy }\end{array}$ & $10(7.2 \%)$ & $28(11.3 \%)$ & $16(10.8 \%)$ & $20(15.0 \%)$ & $7(12.7 \%)$ & $81(11.3 \%)$ & NS \\
\hline $\begin{array}{l}\text { Hearing } \\
\text { Problems }\end{array}$ & $3(2.2)$ & $7(3.0 \%)$ & $3(2.3 \%)$ & $3(\%)$ & $6(10.9 \%)$ & $22(3.2 \%)$ & NS \\
\hline Total & $134(100 \%)$ & $248(100 \%)$ & $\begin{array}{c}147 \\
(100 \%)\end{array}$ & $133(100 \%)$ & $55(100 \%)$ & $717(100 \%)$ & -- \\
\hline
\end{tabular}

Table 3. Self-Reported Symptoms of the Students on the Basis of Duration Spent on Digital Media (NS: Nonsignificant)

Self-reported symptoms of the study respondents on the basis of duration spent on digital media (Table 3)

It was observed that overall the most common selfreported symptom was back and/or neck pain (18.4\%) followed by sleep issues/ insomnia (17.7\%) and headache (17.3). The least symptom reported was hearing problems $(3.2 \%)$. The association between eye $\operatorname{pain}(\mathrm{p}=\mathrm{o.01})$, sleep issues/ insomnia( $\mathrm{p}=\mathrm{0.04})$ and back and/or neck pain $(\mathrm{p}=0.04)$ was found to be statistically significant to the duration spent by the patients on digital learning.

Association between self-reported problems, age and duration of device usage (Table 4).

The multiple linear regression model to analyze the Association between d Self-Reported Problems, age and Duration of device used revealed that good knowledge scores were significantly associated with age $(\mathrm{p}=0.04)$ and the duration of device used $(\mathrm{p}=0.02)$.

Relationship between self-reported health problems and hours of device usage (Table 5)

A positive, linear, great strength of association ( $\mathrm{r}$ : $+0.747)$ and a significant relationship $(\mathrm{p}=0.037)$ was found between Self-reported health problems and the hours of device usage using the Pearson's correlation coefficient (Table 5).

\begin{tabular}{|c|c|c|c|c|}
\hline Predictor & $\begin{array}{c}\text { Coefficie } \\
\text { nt }\end{array}$ & SD & t & $\begin{array}{c}\text { P } \\
\text { value }\end{array}$ \\
\hline \multicolumn{4}{c|}{ Self-Reported Problems } \\
\hline Constant & 44.27 & 5.26 & 67.21 & 0.00 \\
\hline Age & -4.32 & 3.11 & -1.43 & $0.04^{*}$ \\
\hline $\begin{array}{c}\text { Duration of } \\
\text { Device } \\
\text { Used }\end{array}$ & 1.09 & 0.33 & 1.00 & $0.02^{*}$ \\
\hline
\end{tabular}

Table 4. Association between Self-Reported Problems, Age and Duration of Device Usage

\section{DISCUSSION}

In the present study, it was revealed that the most common health problem reported among college going students in Delhi-NCR, India was Back and/or Neck pain $(18.4 \%)$ and this primarily is due to poor posture while using their devices. This finding is also suggestive of the fact that students prefer viewing comfort more than postural comfort. These results is in agreement with Dol KS who reported that $21.1 \%$ and $31.4 \%$ of university students complained of pain in their shoulder and neck due to usage of internet, respectively. ${ }^{9}$ Similar results were also observed by Waersted $\mathrm{M}$ et al. ${ }^{10}$ However, it was observed by Madeleine $\mathrm{P}$ et al. ${ }^{11}$ among computer users that the hand and forearm regions were more susceptible to physical pain resulting from computer as compared to 


\begin{tabular}{|c|c|c|c|c|}
\hline Relationship Between & & $\begin{array}{l}\text { Karl Pearson's } \\
\text { coefficient of } \\
\text { correlation }\end{array}$ & CI & P Value \\
\hline $\begin{array}{l}\text { Self-reported health } \\
\text { problems }\end{array}$ & $\begin{array}{c}\text { Hours of Device } \\
\text { Usage }\end{array}$ & +0.747 & $0.87-45.84$ & $0.037^{*}$ \\
\hline
\end{tabular}

Table 5. Relationship Between Self-Reported Health Problems and Hours of Device Usage

the neck/back region.

Most of the students(34.6\%) reported using digital media for 1-4 hours on an average. Such durations are acceptable as usually the college gets over in the afternoon/early evening and in particular mobile/laptop usage in college premises except for educational purposes is not allowed. Such results are consistent with Anderson KJ et al. ${ }^{12}$ who stated that the typical Internet-using student uses the internet for 100 minutes per day. Similarly, Perry TT et al. reported that $43.8 \%$ of university students used the internet for atleast one hour a day. ${ }^{13}$ In contrast, Wang $Q$ et al. ${ }^{14}$ reported that that $45 \%$ of the college students admitted that they were spending spent 6-8 hours per day checking social media sites, while $23 \%$ spent more than 8 hours; $20 \%$ spent $2-4$ hours and only $12 \%$ spent less than 2 hours on this task. The results indicate that students need to be constantly reminded about the duration of their course regarding the benefits of physical exercise.

It was observed that social media (35.9\%) was the most preferred digital media used by the students and is in agreement to Sponcil M et al. who reported that $45 \%$ of college students are using social media site at least once a day. ${ }^{15}$ This is consistent with the statement that the use of internet is increasing over time. Such figures are also expected to rise as universities include online courses for their students.

This study is prone to certain limitations, one of them being the lack of generalizability due to the selection of a convenience sample. There is also a tendency to either over or under-report self-reported health problems which might have affected the results. However, the possibility for such an event was significantly redcued as confidentiality of the data was assured and no personal data was obtained from the students. Despite such limitations, the results of the present study promotes future opportunities and adds data to existing literature documenting the self-reported health problems and digital media usage among college students.

\section{CONCLUSION}

With the results of the present study, it is important that college students be advised regarding the ill effects on the used of digital medium without taking proper precautions. The need of the hour is to educate the students and encouraging them to limit their use and adopt healthy lifestyle choices.

\section{REFERNCES}

1. Farley T. Mobile Telephone History. Telektronikk 3/4; 2005. Available from: http://www.privateline.com/wpcontent/uploads/2016/o1/ TelenorPage 022-034.pdf. [Last Accessed on $15^{\text {th }}$ January, 2020]

2. Ifinedo, P. Applying uses and gratifications theory and social influence processes to understand students' pervasive adoption of social networking sites: Perspectives from the Americas. International Journal of Information Management 2016;36:192-206.

3. Bekalu MA, McCloud RF, Viswanath K. Association of Social Media Use With Social Well-Being, Positive Mental Health, and Self-Rated Health: Disentangling Routine Use From Emotional Connection to Use. Health Education \& Behavior 2019;46(2S):69S- 8oS. https://doi.org/10.1177/1090198119863768

4. Hall JA, Kearney MW, Xing C. Two tests of social displacement through social media use. Information, Communication \& Society 2018;22(10):1396-413. https://doi.org/10.108o/1369118X.2018.1430162

5. Subrahmanyam K, Reich SM, Waechter N, Espinoza G. Online and offline social networks: Use of social networking sites by emerging adults. Journal of Applied Developmental Psychology 2008;29:420-33. https://doi.org/10.1016/j.appdev.2008.07.003

6. George DR, Rovniak LS, Kraschnewski JL. Dangers and opportunities for social media in medicine. Clin Obstet Gynecol. 2013;56(3):453-62.

7. Jadhav HC, Dodamani AS, Deokar RN, Bhandari RC, Khobragade VR, Agrawal AS. Patterns of Mobile Phone use and Self-reported Health Problems among Adults 
Visiting a Private Dental Institute. Int J Sci Stud 2020;8(1):1-5.

8. IBM Corp. Released 2010. IBM SPSS Statistics for Windows, Version 19.o. Armonk, NY: IBM Corp.

9. Dol KS. Fatigue and pain related to internet usage among university students. J Phys Ther Sci. 2016; 28(4): 1233-7. https://doi.org/10.1589/jpts.28.1233

10. Waersted M, Hanvold TN, Veiersted KB: Computer work and musculoskeletal disorders of the neck and upper extremity: a systematic review. BMC Musculoskelet Disord, 2010, 11: 79.

11. Madeleine P, Vangsgaard S, Hviid Andersen J, et al. : Computer work and self-reported variables on anthropometrics, computer usage, work ability, productivity, pain, and physical activity. BMC Musculoskelet Disord. 2013, 14: 226.
12. Anderson KJ. Internet Use Among College Students: An Exploratory Study. Journal of American College Health https://doi.org/10.108o/07448480109595707 13. Perry TT, Perry LA, Hosack-Curlin, K. Internet use by university students: an interdisciplinary study on three campuses. Internet Research 1998:8(2):136-141. https://doi.org/10.1108/10662249810211593

14. Wang Q, Chen W, Liang Y. The Effects of Social Media on College Students. 2011.MBA Student Scholarship. 5. (Online Article). Available from: https://scholarsarchive.jwu.edu/mba_student/5 [Last Accessed on $12^{\text {th }}$ January, 2020]

15. Sponcil M, Gitimu P. Use of social media by college students: Relationship to communication and selfconcept. Journal of Technology Research 2013;4:1-13. 